\title{
LA MALA LECHE QUE LAS PARIÓ: CIUDADANÍAS NEOLIBERALES EN LA POESÍA CHILENA DEL SIGLO XXI ${ }^{1}$
}

\author{
Biviana Hernández \\ Universidad Academia de Humanismo Cristiano, Santiago de Chile, Chile \\ bhernandezo@docentes.academia.cl \\ Francisco Simon \\ Pontificia Universidad Católica de Chile, Santiago de Chile, Chile \\ fjsimon@uc.cl
}

\begin{abstract}
RESUMEN / ABSTRACT
En este artículo analizaremos los textos poéticos Cobijo de Felipe Ruiz, [guión] de Héctor Hernández y Cuerpo perforado es una casa de Gustavo Barrera, bajo el signo de una subjetividad infantil malograda, que se reapropia de uno de los grandes significantes de la tradición literaria chilena, como es la casa, para elaborar desde allí distintas ficciones en torno a los modos en que los niños del Chile actual habitan e internalizan en sus propios cuerpos el conjunto de la historia social que les ha tocado vivir como hijos enfermos y bastardos de la cultura de libre mercado, consolidada en nuestro país durante el proceso de transición a la democracia.

Palabras Clave: poesía chilena, casa, infancia, violencia, posdictadura.
\end{abstract}

$1 \quad$ Este artículo ha sido escrito en el marco del proyecto FONDECYT 1160191 "Llaneros solitarios, fisiatras y sampleadores: artes poéticas, manifiestos y proclamas de la poesía chilena (1950-2015)”, cuya investigadora responsable es Magda Sepúlveda y quienes suscriben, coinvestigadores. 
La mala leche que las parió: Neoliberal Citizenships in the Chilean Poetry of THE TWENTY-FIRST CENTURY

In this article we will analyze the poetic texts Cobijo by Felipe Ruiz, [guión] by Héctor Hernández and Cuerpo perforado es una casa by Gustavo Barrera, following the idea of a childish and spoiled subjectivity, that reappropriates one of the most important signifiers of Chilean literary tradition, such as the house, to elaborate from that place different fictions concerning the ways in which Chilean children today inhabit and internalize in their own bodies the whole social history that they have had to experience as children of the ill and bastard offspring of the free market culture, consolidated in our country during the process of democratic transition.

KEYWORDS: Chilean poetry, House, Childhood, Violence, Posdictatorship.

Recepción: 08/03/2017

Aprobación: 12/07/2017

\section{PARA COMENZAR...}

En enero de 1979 se creó en nuestro país el Servicio Nacional de Menores (Sename) con el objeto de resguardar, por una parte, los derechos de niños y adolescentes vulnerados en su entorno familiar; y por otra, prestar alternativas de reinserción social para aquellos jóvenes que se hallasen en problemas con la ley. Sin embargo, y a casi cuatro décadas desde su puesta en funcionamiento, hoy esta institución hace ruido en los medios de comunicación debido a la publicación de hechos y datos que han escandalizado a la opinión pública. Según el Informe anual (2016) del Instituto Nacional de Derechos Humanos, entre los años 2005 y 2016 fueron 243 jóvenes quienes fallecieron internados en residencias del Sename. Luego, a esto se suman deficiencias administrativas, denuncias de maltrato, condiciones insalubres de habitabilidad, así como también escasa profesionalización de los funcionarios a cargo. Problemas todos que han puesto en duda la misión de este organismo en tanto protector de la infancia, al mismo tiempo que, desde una perspectiva cultural, han hecho de la infancia vulnerada un lugar de debate con respecto a los desafíos todavía vigentes que restan en el país para consolidar un Estado garante de derechos tras el retorno a la democracia ${ }^{2}$.

2 En su texto Criminal (2003), el poeta Jaime Pinos inventa la voz de Roberto Martínez Vásquez, apodado por la prensa sensacionalista como “el psicópata de La Dehesa", 
Por otra parte, desde la crítica literaria, podemos decir que los imaginarios de la infancia en la poesía chilena son ricos en la elaboración de figuras y propuestas críticas que desde una perspectiva política vinculan experiencia y narración; realidad y lenguaje, de acuerdo con la convicción de que todo texto literario se encuentra "de algún modo lastrado por la ocasión en que se produjo, por las simples realidades empíricas de las que emergió" (Said 54). Así, por ejemplo, destacamos la lectura de Claudio Guerrero acerca de $L a$ pieza oscura (1963) de Enrique Lihn, al señalar cómo la infancia configura allí la identidad de un yo "que intenta construirse, encontrar su espacio y crecer" (16), en un mundo asediado por la "deuda con un presente que se vive de modo traumático" (11). La infancia es un tropo que tensiona los mecanismos de mediación entre realidad y lenguaje, formulando una subjetividad que regresa sobre su historia para simbolizar el origen de aquellas ruinas que habita en el presente, pues, como sostiene Giorgio Agamben, la infancia "se constituye ella misma mediante su expropiación efectuada por el lenguaje al producir cada vez al hombre como sujeto" (66), de modo que el devenir infantil en la escritura poética conlleva revisitar y reinventar la vida, desde ese momento limítrofe en que un individuo se hace consciente y se representa su propia vulnerabilidad.

En este marco, que busca aproximar discusiones de tipo sociocultural y crítico-literarias en torno a la infancia, el presente trabajo tiene como objetivo analizar la producción de tres poetas vinculados a la promoción novísima del 2000 que han asumido la creación de voces infantiles vulneradas ${ }^{3}$. Nos referimos a los textos Cobijo (2005) de Felipe Ruiz, [guión] (2008)

destacando cómo sus prácticas criminales responden a la precariedad que debió habitar durante su infancia en las residencias del Sename: "si alguna vez me dieron algo / fue la condena de crecer en el encierro. / Desde niño, una cárcel tras otra. / Hogares, las llamaban. / Si alguna vez me dieron algo / fue tan sólo para sacarse las fotos. / Un ejemplo de rehabilitación, decían entonces, / mientras sonreían a la cámara" (14).

El término de poetas "novísimos" fue acuñado por Héctor Hernández para referirse a la promoción de autores que comienzan a publicar sus primeros textos desde el año 2000, entre los que se cuentan, además de él mismo, también otros como Paula Ilabaca, Felipe Ruiz, Gladys González y Pablo Paredes. De acuerdo con Hernández, todos ellos “escriben desde la desobediencia de sus quehaceres hogareños, estudiantiles, familiares y hasta juveniles. Y a pesar de todo siguen con la palabra como resistencia e intervención" ("Panorama", párr. 1). Es decir, estos poetas recurren a la imaginación doméstica en sus textos para criticar desde ese lugar micropolítico las marcas que el autoritarismo y el neoliberalismo han dejado sobre la cultura chilena contemporánea. 
de Héctor Hernández y Cuerpo perforado es una casa (2011) de Gustavo Barrera; todos ellos caracterizados por formular la subjetividad de niños huérfanos, psicóticos, abortados o travestidos, habitantes de un espacio doméstico disfuncional y malogrado. Lo que nos interesa examinar son las formas de enunciación utilizadas por estos poetas para simbolizar la infancia y los posibles significantes asociados a la representación infame que hacen de la figura poética y social de la casa. Nos parece que tanto la niñez como la figura de la casa son dos isotopías centrales en la escritura -y el arte poética- producida por estos autores y, por ello, queremos poner en diálogo estos textos con el campo cultural, a fin de leer las tensiones discursivas y los valores ideológicos en disputa desde donde estos poetas están imaginando y reinventando la sociedad chilena contemporánea.

Tanto la enunciación infantil como la figuración abyecta del espacio doméstico son dos dimensiones a través de las cuales se simbolizan, los efectos nocivos que ha ejercido la economía neoliberal y sus tecnologías massmediáticas sobre la articulación de la subjetividad, la familia y la comunidad chilena actual. Las subjetividades infantiles elaboradas por Ruiz, Hernández y Barrera son hijas de un país en el que la justicia social ha sido subsumida por la ley del mercado. De allí que sus escrituras inventen de forma recurrente la voz de niños monstruosos y hambrientos; guaguas feas, malparidas, cuyos hogares son hábitat del vicio y el abuso permanente. Se trata de una estrategia tropológica mediante la cual estos poetas verbalizan el lugar de herida y polémica que mantienen con el Chile de posdictadura, reconfigurando la tensión arraigo-desarraigo de su entorno vital, al posicionarse como habitantes de una casa-ciudad que moviliza el drama social latente de un sujeto precarizado y desplazado a espacios cada vez más reducidos, "bajo la condición de su endeudamiento y la eternización de su rol en la generación de dinero" (Moncada 178). En este escenario, la figura de la casa en la poesía de los 2000 es el signo de una habitabilidad fracasada o, incluso, imposible, donde se materializan las formas psíquicas de construcción de una historia e identidad nacional (Brito 13) correlativa al proceso de malformación que significa poblar una casa-ciudad neoliberal, mediada por el consumismo, la privatización del derecho público y la atomización individualista de la comunidad.

La producción de un tipo de infancia trastornada debido a la destrucción neoliberal del "nido lárico" constituye un tópico no solo presente en las escrituras de Ruiz, Hernández y Barrera, sino que existe un amplio corpus de producciones poéticas contemporáneas que han optado por representar 
la cultura chilena desde este lugar ${ }^{4}$. Por ejemplo, esta situación se reitera en textos como El baile de los niños (2005) de Diego Ramírez, El final de la fiesta (2005) y Mi hijo Down (2008) de Pablo Paredes, Patria asignada (2010) de Víctor Munita Fritis o PAF (2011) de Tamym Maulén, por mencionar algunos. En todos estos textos resulta isotópica la formulación de una voz enunciativa que, desde la posición del sujeto infante, hace hablar las prácticas de violencia política que se ejercen en nuestro país y que parecen haberse naturalizado como parte del proceso de formación que todo niño debe aprender para convertirse en ciudadano chileno. Por tanto, esperamos que el análisis y las conclusiones propuestas por este trabajo sean relevantes para reflexionar no solo sobre el corpus específico que abordaremos y su vinculación con el entorno social en que se producen, sino que, además, sirvan para pensar sobre problemáticas de mayor alcance cultural, que resultan fundamentales en un sector importante de la poesía chilena editada durante los últimos años.

\section{FELIPE RUIZ: "QUÉ POBRE LECHE ME HAS DADO, MAMÁ”}

En el caso de Felipe Ruiz (Coronel, 1979), un primer elemento que resulta llamativo es el contrasentido fundamental que existe entre el título de su texto, Cobijo, y las condiciones familiares y materiales habitadas por el sujeto de la enunciación. En este texto, se tornan grotescas las viejas alegorías familiares de la nación para representar, en cambio, un mundo regresivo, en el cual las condiciones mínimas de civilización han sido atrofiadas. Contra todo tipo de cobijo y de resguardo familiar, el poeta resuelve crear un espacio doméstico - la casa- trazado por la violencia de las relaciones incestuosas donde todos resultan ser "hijastros de madres / todos padres de nietos" (73). En Ruiz, la casa es imaginada como un vertedero, donde "la miseria es carnicera per se" (22) y donde tanto el sujeto de enunciación como el colectivo que representa a todos los de "su especia", viven en un constante estado de hacinamiento que ha terminado por deshumanizar las relaciones afectivas allí experimentadas:

padre e hija a una cama

nos asimos

nos cansó el hacino [...] 


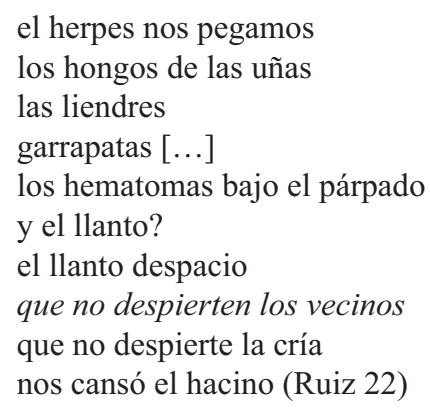

En los márgenes de este espacio familiar marcado por una genealogía incestuosa, el hablante imagina su propio cuerpo y el de su casa como un cuerpo infecto y ulcerado; un hogar en el que el hacinamiento ha hecho devenir a la familia en un conglomerado de parásitos: hongos, liendres y garrapatas. Por eso, la voz infantil producida por Ruiz no puede sino reconocer su biografía como la historia de un feto abortado: "ya no recuerdo / el nombre que iban a ponerme / antes que me rasgaran / de los pies a la cabeza" (62). A contrapelo de cualquier novela de formación ${ }^{5}$, en Cobijo el signo del incesto representa un origen abyecto del que resulta imposible salir, debido al trauma que le conlleva al sujeto habitar una casa donde el sufrimiento y el castigo son sus afectos más recurrentes: "sufrí desde que tengo memoria / hasta sufrir de memoria" (51); "desde pequeño conocí el cinturón y su locura / [...] / sin saber por qué / nos castigaron / hasta cuando santos" (52) .

5 Diamela Eltit, evocando la novela de formación del niño delincuente en El río (1962) de Alfredo Gómez Morel, comenta la situación mediática de Cristóbal Cabrera Morales, conocido como "el Cisarro", advirtiendo de qué manera el (otro) niño de la historia "es mostrado y producido como objeto por los medios y los poderes fácticos, que en pleno siglo XXI lo usan y exhiben para producir el pánico social: mudo, desconocido, carente de subjetividad [...] "un mal salvaje" que profundiza el terror de la mirada (burguesa) hacia los sectores populares, donde se puede inferir que "hasta los niños son criminales consumados" (265).

La representación de la casa como espacio permanente de la violencia es un tópico también elaborado por Tamym Maulén en PAF (2011), donde la voz poética simboliza con ironía cómo los golpes y abusos del padre constituyen el relato elemental a partir del cual se articula su biografía. Así, por ejemplo, el sujeto señala cómo "Yo quiero que mi padre me pegue siempre" (39), mientras añade que "Puro amor familiar, ese el título del cuento / El nombre que mi padre tatuó con una cachetada / En la mejilla izquierda de mi corazón: -PAF" (40). 
El niño que habla en la poesía de Ruiz hace "metafísica de la miseria humana" (68), como si las causas y propiedades últimas del ser fuesen, justamente, las de la miseria humana. Desde esta reflexión, el poeta reconstruye el discurso cultural de toda una época, a fin de visibilizar la precarización y vulnerabilidad de la infancia en un contra-lar mercantilizado y opuesto a la imagen del nido protector del hogar, como ocurría en la imaginación utópica del poeta lárico durante los años sesenta ${ }^{7}$. Así se explica que el entorno vital del sujeto poético, en la tensión arraigo-desarraigo, redunde en representaciones de "imágenes precarias", donde "todos nacen muertos" y donde "nadie es de nadie / nadie de nadie" (73). En Ruiz, como en las otras voces infantiles de los novísimos poetas del 2000 , la figura de la casa politiza la unión incestuosa entre economía y deseo, toda vez que el incesto tiene como consecuencia la construcción de la periferia en los límites materiales de una "vivienda de emergencia", lugar donde se agrupa la masa incivil, "librada a la desafiliación íntegra a la comunidad, sin deseo de pertenencia, pues ya no se sabe bien a qué pertenecer" (Brito 136).

En la escritura de Ruiz, el incesto marca la anomia y la violencia habitadas por el sujeto, que hace coincidir su vivienda de emergencia periférica con la experiencia de muerte intrínseca que le produce reconocerse como parte de una familia que, en sí misma, se encuentra en situación de emergencia. Por tanto, al vincular la habitación de un mundo marginal con la genealogía en el incesto de la que desciende, lo que hace este poeta es formular un lugar de enunciación fundado fuera de las narrativas del desarrollo y el progreso transmitidas por el discurso tecnocrático de los poderes fácticos ${ }^{8}$.

7 Recordemos a Teillier en su manifiesto de 1965, "Los poetas de los lares": "los poetas de los lares pretenden afirmarse en un mundo bien hecho, sobre todo en el del mundo del orden inmemorial de las aldeas y de los campos, en donde siempre se produce la misma segura rotación de las siembras y cosechas, de sepultación y resurrección, tan similares a la gestación de los dioses [...] y de los poemas [...] De ahí también la nostalgia de los "poetas de los lares", su búsqueda del reencuentro con una edad de oro, que no se debe confundir sólo con la de la infancia, sino con la del paraíso perdido que alguna vez estuvo sobre la tierra" (54).

La mirada crítica con que Ruiz contrasta el éxito supuesto de la economía neoliberal para la sociedad chilena de posdictadura se reitera en su texto Fosa común (2008): “A los nueve años los ciudadanos ya son aptos para comprender / la diferencia entre el trabajo y el placer / por lo que serán conducidos a cantar en las iglesias / y con sus bocas entre abiertas podrán recordar levemente / a qué sabía el paracaídas que los trajo desde el último grito de / rebeldía de sus padres hasta la ciudad de malles y suburbios" (20). 
Pero en el universo poético de Cobijo, pobreza e incesto no solo son signos de la experiencia familiar del hablante, sino que, además, articulan una alegoría grotesca del estado precultural al que ha devenido la clase popular, la comunidad de sujetos periféricos durante la transición democrática en Chile. Ruiz instala su voz en el espacio de una marginalidad urbana que colinda con el subdesarrollo, pero todavía más, con la sub-humanidad. Así, por ejemplo, compara las soluciones habitacionales subsidiadas por el Estado desde los años noventa para los sectores vulnerables con los que fuesen antes, en plena dictadura, los centros de reclusión y tortura:

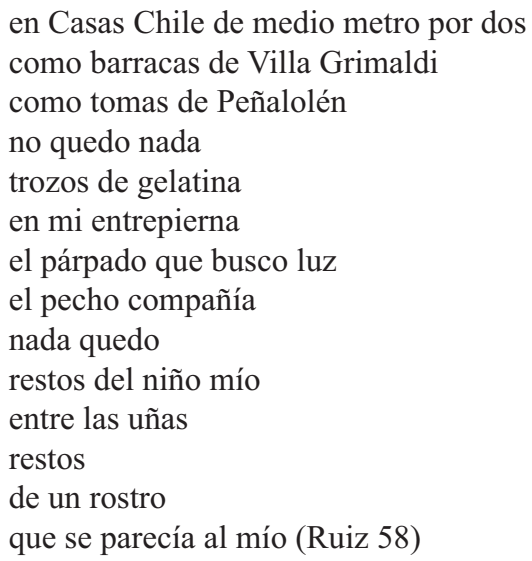

Recurriendo a la voz de una madre lamentándose por la pérdida de sus hijos no nacidos, Ruiz habla de la indignidad padecida por los sujetos populares, primero, durante la dictadura, y más tarde, también con el retorno de la democracia. El cuerpo malherido de esta madre y su habla discordante, carente de sintaxis, son recursos con los que el poeta elabora la historia de tortura, represión y desalojo que aquellos han experimentado durante las últimas décadas en nuestro país. Así, en una trama de hogares rotos y afectos familiares sometidos a la barbarie del incesto, Ruiz ficcionaliza el devenir de toda una comunidad de pobladores a los cuales no les ha quedado nada, nada de dignidad, hacinados como están en sus viviendas de miseria y degradación, sin más posibilidades que el apremio por la sobrevivencia diaria. Situación frente a la cual el sujeto no puede más que exclamar, iracundo: "cuánta destrucción en los nidos americanos / cuántas patrias arruinadas $y$ marchitas" (55). 
En este escenario, la madre es consciente del origen y destino de su hijohermano al utilizar la expresión "mala leche", cuyo sentido de uso popular se basa en la creencia de que la leche materna influye tanto en la salud como en la personalidad del bebé. En algunas regiones de América Latina, la expresión se usa como sinónimo de "mala suerte". Se dice así porque el embarazo no deseado se consideraba como un acto desafortunado; de allí su sentido generalizable a cualquier situación en la que sucede algo no planificado. En los versos de Ruiz, la madre sabe que el niño, su hijo, crecerá con la mala leche de su alimento descompuesto y con la "mala suerte" de ser un sujeto popular en el Chile de posdictadura:

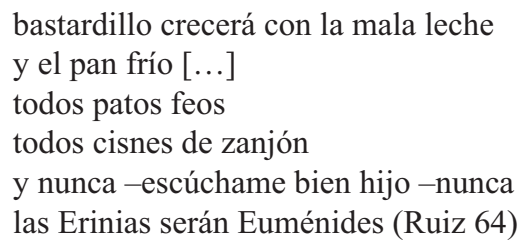

El lamento con que la madre prevé el destino de su descendencia y la lección que le enseña al hijo -a saber, que las Erinias nunca serán Euménides-, son marcas de un determinismo social con que Ruiz elabora la situación insalvable de precariedad familiar y política en la que se halla esta familia. En la Orestiada de Esquilo, la transformación de las Erinias en Euménides metaforizaba el momento en que se inaugura la justicia conciliatoria frente al modelo vengativo que caracterizaba al derecho predemocrático. De suerte que en el universo simbólico de Cobijo, el hecho de que las Erinias, las furias vengadoras, nunca se transformen positivamente, implica la fijación de esta familia en un mundo gobernado todavía por el despotismo. La miseria en que habitan estos sujetos es un signo de la falta de justicia que, en el Chile actual, mantiene todavía a los sectores populares postergados del bienestar que debía haberles traído el retorno de la democracia ${ }^{9}$.

9 La representación abyecta con que Ruiz elabora el porvenir político de los niños populares criados tras el retorno de la democracia en Chile coincide con la imaginación de Pablo Paredes, quien simboliza la ciudadanía posdictatorial mediante la creación de un cuerpo infantil horroroso y enfermo. En El final de fiesta (2005), el sujeto dice "Gracias por bailar conmigo / y decirme / princesa son las doce y sigue tan linda, / porque yo sé que soy feo [...] que tengo el cuerpo horrible / como un mapa físico de Chile" (47-8). Y también, en Mi hijo Down (2008), escribe con ironía cómo "Cuando nacen las criaturas chilenas / las criaturas 
Los patos feos, cisnes de zanjón, con que Ruiz metaforiza las huerfanías de los niños sin casa en el Chile neoliberal de los 2000, solo encuentran como destino espacios cargados de podredumbre: "tiestos de basura", "orfelinatos" y "perreras" (63), donde estar o pasar la vida. El niño que emplaza la letra poética de Cobijo asume la identidad de un ser anómalo, producto de una violación: es el hijo de su abuelo, es decir que su padre es el padre de su madre: "mi padre abuelo/ padre y madre" (21), sabiendo que su madre ha sido, como él, otra víctima del acoso sexual permanente del padre, y que el niño sin cobijo que habla en el lenguaje agónico de la poesía actual, entiende, desde la adultez, los alcances del trauma que implica el hecho de la violación reiterada. Por eso aquí no solo el sujeto, sino que todos los otros de "nuestra especia", "mis hermanos lesbianas / mis hermanas travestis" (47), padecen el mismo insoslayable destino del desecho:

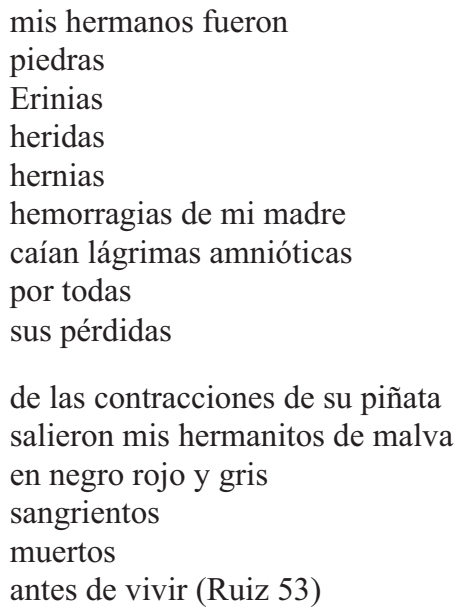

La biografía producida por esta voz infantil destaca cómo ella y todos sus hermanos descienden del mismo cuerpo materno convertido en piñata, es decir, en un cuerpo golpeado, apaleado. Ruiz recurre a un lenguaje brutal, ocupado por imágenes de miembros ulcerados y de niños viscosos y ensangrentados, con los que habla acerca de los efectos que ha producido la marginalización

vivas del país / todas nacen como si fueran chinas / todas nacen feas como si fueran chinas ahogándose / todas las personas piensan esto, / ninguna lo dice / porque piensan que un bebé es lo más bello que puede / pasarle a la patria” (23). 
urbana, económica y política de los pobladores durante la posdictadura. Por eso, este sujeto nombra a sus hermanos no solo como niños abortados, sino que también como detenidos desaparecidos. Él se pregunta: “dónde están? / dónde mis hermanos! / dónde están?" (44), haciendo coincidir su voz con la protesta de las agrupaciones de familiares de detenidos desaparecidos, para mencionar así la pervivencia de la violencia histórica ejercida contra los pobladores. En el mundo elaborado por este poeta la dictadura no se ha acabado aún, sino que continúa ejerciéndose, pero esta vez a partir de las políticas habitacionales de la Concertación que, en vez de recobrar la lucha y resistencia sociales, han terminado por desplazar toda esa memoria popular hacia los confines periféricos de la ciudad.

El fin del ideal político que unía a pobladores y a estudiantes, en aras de un futuro más justo y equitativo, tópico recurrente en la poesía publicada tras el retorno de la democracia (Sepúlveda 56) ${ }^{10}$, encuentra en la subjetivación infantil de Felipe Ruiz la carga simbólica que portan los sentimientos de rabia e indignación del sujeto poblador que aún resiste. Y es que así como Ruiz elabora la derrota, también apuesta por la reivindicación. El hablante aquí no solo es un niño abortado, sino uno que también le reclama a su madre el haberse dejado derrotar: "qué pobre leche / me has dado / mamá" (46), señalando cómo el origen de su reclamo se halla en el abandono total de sus derechos fundamentales: "guagua que no llora no mama / perro que ladra no muerde // pero lloré y no mamé por eso ahora ladro y muerdo de rabia (51). Así, este sujeto polemiza con la ética neoliberal del "cada quien se rasca con sus propias uñas", al representar sobre sí la precarización que ha conllevado para los pobladores este tipo de socialización individualista y enajenada.

En este sentido, y si bien el lenguaje grotesco con que se expresa el sujeto poético pareciera descreer de cualquier posibilidad de restitución social, en sus últimas estrofas hace pervivir la memoria de los pobladores. La indignación es el arte poética del texto, el deseo que moviliza su palabra: "ENTRE SUPER CARRETERAS Y SEÑALÉTICAS / ENTRE CUBOS Y NÚMEROS / CARTONEA LA POESÍA” (72) dice la voz poética, mientras añade cómo también aquí "DECONSTRUIMOS LOS ANTIGUOS CANTONES

10 Para Magda Sepúlveda, "la derrota de los pobladores" es un tópico recurrente en la poesía publicada tras el retorno de la democracia, presente "en poetas de la promoción de los 60, como José Ángel Cuevas; de los 70, como Raúl Zurita; o de los 90, como Christian Formoso que dan cuenta del fin de un ideal político que unía a pobladores y estudiantes en pos de un nuevo amanecer" (56). 
DE MI PUEBLO / LA LENGUA COA Y MAPUÑOLA / DE FAMILIAS SUBDESARROLLADAS Y SUBARRENDATARIAS" (68). De este modo, Ruiz reconoce en el trabajo poético la posibilidad de recuperar la memoria de los pobladores postergados, pues en la ferocidad de su lenguaje, en el niño abortado que hace actuar su voz, y también en el hacinamiento habitacional que produce la hiperurbanización del entorno, lo que hace el poeta es rebatir y revertir la verdad histórica que cristalizó en el éxito de la transición democrática tras la implantación de sus políticas públicas subsidiarias. Esto es lo que el sujeto enfatiza tipográficamente en la escritura, al destacar en letras mayúsculas el sentido caótico de aquellas políticas de libre mercado que hacen de la ciudad posdictatorial un espectáculo del subdesarrollo social con sus grandes estructuras viales, "carreteras y señales éticas", que permiten el desplazamiento de las masas proletarias, mas sin modificar su exclusión social ni las diferencias de acceso tanto a la vivienda como a la educación y la cultura (Moncada).

\section{HÉCTOR HERNÁNDEZ: "HOLA, SOY MAMI, ¿QUIERES QUE TE LO META TODO?"}

Siguiendo los pasos de Felipe Ruiz, otro poeta que se destaca por elaborar una crítica del Chile neoliberal es Héctor Hernández (Santiago, 1979), quien en su texto [guión] (2008) ${ }^{11}$ debate los efectos nocivos asociados a la massmediatización de la cultura y al avance de la industria publicitaria sobre la subjetivación contemporánea. Hernández utiliza de trasfondo la escena traumática de una violación como origen del cuerpo enfermo y de la escritura también enferma del poeta (Sepúlveda, Ciudad 249). que reescribe, entre otros textos, el "Padre nuestro", pero alterando el valor religioso de la oración, al corporalizar la figura del padre y permitir que en esa letra desviada el sujeto cuente su historia (Sepúlveda, Ciudad 249); una historia que, al igual que en Felipe Ruiz, da cuenta de una genealogía incestuosa que, en este caso,

$11 \quad$ El texto reúne sus primeros libros: No! (2001); Este libro se llama como el que yo una vez escribi (2002) y El barro lírico de los mundos interiores más oscuros que la luz (2003). A su vez, pertenece al primer tomo de La divina relevación, trilogía compuesta por [guión], [coma], [y punto]. 
ironiza la Ley del Padre mediante la actitud apostrófica del hablante, que lo posiciona como su salvador:

\author{
Padre mío \\ que estuviste en mi cama \\ porque mis sábanas fueron nubes \\ y en ellas ondeaba la sangre \\ de mi penetrante genealogía \\ [h]iciste mi voluntad la tuya \\ [m]e diste mi origen cada noche (Hernández 63)
}

Hernández coincide con Ruiz en representar la voz de un niño abortado, aunque suturando aquel trauma con el travestismo del sujeto en las estrellas pop que mira por la televisión. Se trata de un niño sordomudo que lleva por nombre la letra muda (o "Sordomudaletra") del nombre del autor textual, $\mathrm{H}$ (u Homónimo) ${ }^{12}$ - que se dice parte de una comunidad de niños "enfermos terminales en las calles muriendo por televisión", habitantes de un territorio defectuoso al cual nombra, en femenino, "la Manicomia", donde el sujeto en plural señala que: "Nos decían las Tres Marías / María Thalía / María Lynda / María Paulina Rubio / estamos en la noche / pudriéndonos de risa" (61). El sujeto crea una ficción territorial sobre la base del correlato cristiano de una "Santísima trinidad" metonímica que, en todas sus multiplicidades, lo convierte en "sobreviviente de diversas catástrofes" (Sepúlveda, Ciudad, 250). El enunciante "Hache" de [guión] antes que solo metáfora del silencio, es también una transparencia del habla, pues: "Hache es un tránsito que se silencia de hablar desde lo fónico, pero que habla mentalmente" (Rojas Canouet 74).

En esta metaforización colectiva de una identidad anómala, el niño sordomudo de [guión] se inventa la siguiente autobiografía:

A mi mamita le dijeron

que hay que extirpar el cáncer de raíz

12 Sobre el simbolismo de esta letra en el cuerpo del poema, sostiene Sepúlveda: "[e]n el camino de la memoria y del olvido, la voz debe trazar otro guión para su subjetividad y para ello es necesario reflexionar sobre el alfabeto aprendido. En esta línea, la voz va poetizando sobre la relación entre ciertas letras y su cuerpo. Por ejemplo, $\mathrm{H}$ es la letra del nombre y del apellido del autor, Héctor Hernández, cuya sigla HH es usada también en el libro. H es, además la letra muda y, como tal, el nombre del niño sordomudo $\mathrm{H}$. Asimismo $\mathrm{H}$ es la inicial de homosexual. Por tanto la opción por esta letra es un significante motivado por alusiones múltiples, todas ellas vinculadas al imbunchamiento de lo propio" (Ciudad 249). 


\begin{abstract}
y mataron a su hijo izquierdo
yo me salvé porque era una estrella

Yo no me llamo Walter González Soto

aparezco en la noche como si fuera de televisión

me conocen por María Thalía

mi Síndrome es fatal (Hernández 62-3)
\end{abstract}

Lo interesante de la identificación de este sujeto con personajes como Paulina Rubio o Thalía es que estos nombres le sirven para producir un simulacro de la violencia original de la que ha emergido. Hernández enuncia el travestismo del sujeto como resultado de aquel aborto que se ha realizado su madre y que bien puede ser leído, desde un punto de vista cultural, como una forma de figurar el desmembramiento político que conlleva el impacto de los massmedia. En efecto, en los versos citados este poeta hace del aborto un ideologema que alude a la retórica quirúrgica del "cáncer marxista" empleada por la Junta Militar y por eso añade que el hijo de izquierda ha sido tachado, restando ahora solo él, el hermano de derecha, que con su travestismo en diva pop performa los guiones promovidos por la maquinaria televisiva neoliberal ${ }^{13}$.

Hernández simboliza los efectos que ha producido la televisión en su habla poética, creando una autobiografía delirante que lo salva de reconocer el trauma de su infancia malherida ${ }^{14}$ : "Yo no soy de esos que olvida cosas para recordar porque la casa de mi memoria la sostienen los testimonios de

13 Otro poeta que representa los efectos del sistema neoliberal sobre la ciudadanía contemporánea es Diego Ramírez, quien en El baile de los niños (2005) asocia el éxito de este sistema económico con el fracaso absoluto de la utopía revolucionaria, que en las décadas anteriores alentase la participación política de los jóvenes: "Míreme el consumo descariñado de mis padres / mire lo que ha hecho la publicidad con nuestras formas de caminar, / con nuestras formas de amar en los parques y en las discos / Mire compañero de luchas pasadas / Cómo me duele a mí también la derrota de mi barricada / plástica y bella, al mismo tiempo" (54). En su texto más reciente, Brian, el nombre de mi país en llamas (2015), Ramírez insiste en representar a la juventud como un cuerpo político herido, aunque valora esta vez la resistencia de las protestas estudiantiles: "nosotros que llevamos la molotov iluminando / el centro de nuestros corazones, / entendemos la necesidad de encapucharse las manos, / de verle levemente el brillito de los ojos / cuando triza la ciudad, las vitrinas, los hipermercados. / La fascinación de llevar la delincuencia infantil / de la destrucción como gesto de amor" (32).

14 A propósito, señala Rojas Canouet que la condición delirante y alegórica de la escritura de Hernández es producto del trauma histórico generado por el golpe militar: "ese trauma produce un enmudecimiento ("Historia de la H"). Esta aporía de enmudecerse en el delirio alegórico es el doble juego. Una salida: el delirio, entonces, es una catarsis deconstructiva 
la alucinación" (103). Es decir, recurre al delirio esquizo de la pantalla para evitar racionalizar aquel aborto forzado de su madre, del que procede, así como también el dolor provocado por la violación paterna: "MI PADRE LLEGABA A DESPERTARME EN MITAD DE LA NOCHE // Hola / soy mami / ¿quieres que te lo meta todo?" $(235)^{15}$. Como en los versos de Ruiz, aquí también el incesto es el signo de una regresión del sujeto hacia tiempos preculturales, cuando el Padre aún no asumía el estatuto metafórico del derecho o la moral, ejerciéndose su poder de manera barbárica y despótica. Por eso, a través de la violación incestuosa, el sujeto "profanado" de Hernández simboliza la pervivencia del autoritarismo en la sociedad chilena de posdictadura, aunque acusando esta situación ya no en el hacinamiento al que habían sido relegados los pobladores populares, sino que en el abuso suscitado por la industria massmediática. En la representación de la escena incestuosa el poeta elabora la acción de un padre violador, que resulta convergente con las tecnologías de consumo observadas en la pantalla:

Burbuja Bellota y Bombón no son chicas del montón Son las chicas súper poderosas de Norteamérica que vencen a los villanos con astucia y gracia Millones de niños en el mundo las siguen por televisión y compran su mercadotecnia incluso los cereales Natur que venden acá en Chile Cereales que te hacen fuerte saludable y poderoso Aunque a ellas no les importa que también te hagan cancerígeno con los colorantes prohibidos Total ellas están pintadas con acrílico y látex sintético (Hernández 115-6)

Hernández asume la posición enunciativa de un niño que no solo se ha formado bajo el signo del incesto, sino que también bajo las técnicas del consumo neoliberal. Frente al televisor, el sujeto hace coincidir el abuso paterno con la toxicidad de la mercadotecnia, pero no enuncia tales actos como formas

de la mudez. Es decir, el pánico ("asombro" de Sordomudoniño) del trauma se contrarresta con la proyección del imaginario (siluetas de sujeto) desde lo delirante" (73).

15 Del mismo modo que Hernández, en Patria asignada (2010) de Víctor Munita Fritis también se reitera la producción de un sujeto infantil que desde su nacimiento ha sido violado, pero que recurre a la televisión como un medio para anestesiar los daños de los que ha sido objeto. En este texto, Munita escribe cómo "Aún no he nacido / y ya desean penetrarme" (23), mientras añade más tarde que "Yo comía harina tostada con leche y calmaba / las preguntas del hambre viendo tele / la piel estaba llena de gusanos, eso pensaba y en realidad a esa edad no sabía que eran las secreciones torcidas, la miseria y el espanto" (91). 
de violencia, y esto es, precisamente, aquello que lo tiene alucinado. Valga decir que en su fantasía televisiva normaliza estos padecimientos como parte de la actuación que debe realizar en tanto telespectador. El guion que este sujeto performa se halla intervenido por la fluidez del discurso publicitario, que oblitera su capacidad de negación frente a los mandatos agresivos de la ley. En otras palabras, el sujeto comprende que su comida lleva cáncer, pero mastica y consume ese daño anestesiado.

Para Slavoj Žižek, uno de los efectos culturales que ha producido el capitalismo global es que, gracias a la repetición incesante que hacen los medios de guerras, catástrofes y de todo tipo de escenas de muerte, tales imágenes son incapaces hoy de ser interpretadas como un Real traumático. Por eso, estos serían los tiempos del sujeto postraumático, "una Cosa enigmática, impenetrable, totalmente ambigua, hasta el punto de que no se puede hacer otra cosa que oscilar entre atribuirle un sufrimiento inmenso o una bendita ignorancia" (311-2). Si prestamos atención a la estructura delirante del hablante poético de Hernández, parece posible sugerir que este es, precisamente, un niño postraumático, formado por aquella escuela incesante de violencia que mira asombrado por las pantallas del televisor. En el espacio familiar manifiesta su deseo por "hacer una casa local sobre una piedra de papel locura" (37). No obstante, lo que se impone por sobre la utopía, la imaginación o el propio delirio, es la impertérrita materialidad de un televisor que metafóricamente actúa como "nuestra mascota preferida", y a la cual sus miembros dejan recorrer "toda la casa e incluso que se suba a las camas" (83). Por eso, en la familiaridad afectiva que mantiene el sujeto con el aparato televisivo, en esta alucinación donde vive travestido, se vuelven indistinguibles los ejercicios de violencia que desde allí le son transmitidos:

ALGUIEN QUIERE LIMPIAR LA CASA

ALGUIEN QUIERE LIMPIAR LA PATRIA

ALGUIEN QUIERE LIMPIAR EL CORAZÓN

$[\ldots]$

REPITE CONMIGO:

Creo en la limpieza porque

Drive MaticProgress

es insuperable contra las manchas

Creo en la Limpieza porque

Clorox tradicional 
desinfecta limpia y blanquea

$[\ldots]$

\section{DRIVE MATIC PROGRESS EDICIÓN LIMITADA EL DETERGENTE RACIONAL (Hernández 76)}

En estos versos, Hernández recoge dos modelos discursivos, el "Credo" católico y la retórica publicitaria, para elaborar desde aquella intersección de textos culturales el guion instructivo con que trabaja la industria televisiva. De tal modo, señala cómo la publicidad ha intervenido su subjetividad haciéndolo imitar los eslóganes de una manera religiosa pero, al mismo tiempo, racional: al final de la estrofa subraya cómo el consumismo es un discurso racional, que hace uso de un simulacro de lógica para persuadir al consumidor. Sin embargo, a pesar de que aquí el sujeto incorpora el signo amenazante vinculado al discurso que observa por las pantallas, no reconoce cuál es la agencia de poder implicada. "Alguien" quiere limpiarlo a él y a su familia, pero se trata de un poder que el sujeto solo puede enunciar a través del lenguaje despolitizado de la publicidad. Esta retórica ocupa su voz, no puede distanciarse de ella y se convierte, entonces, en una "vida desperdiciada" que conlleva, al decir de Zygmunt Bauman, el devenir de la propia subjetividad en un desecho del mercado neoliberal ${ }^{16}$. Este sujeto dice que desea "rodear a la herida de ficciones / para que también se ficcionalice" (54); valga decir que acude al lenguaje neoliberal para desdibujarse con los significantes vistos en la pantalla, haciéndose parte de un flujo en el que su dolor ya no signifique nada.

16 Precisamente, en su libro Vidas desperdiciadas, Bauman argumenta que "[1]os productos comerciales de consumo encarnan involuntariamente la paradoja suprema de la cultura de los residuos: Primero, es el horroroso espectro de la desechabilidad -de la superfluidad, el abandono, el rechazo, la exclusión, el desperdicio- lo que nos mueve a buscar la seguridad en el abrazo humano. Segundo, de esa expedición es de la que nos desviamos hacia los centros comerciales. Tercero, es la propia desechabilidad, mágicamente reciclada de enfermedad terminal en terapia, lo que allí encontramos y lo que sentimos el impulso de llevarnos a casa" (168). 


\section{GUSTAVO BARRERA: "YO HUBIESE PEDIDO SER DE PLÁSTICO”}

En consonancia con la subjetividad postraumática delirante y desechable, elaborada por Héctor Hernández, nos referiremos, por último, a Cuerpo perforado es una casa de Gustavo Barrera (Santiago, 1975), un texto que también debate los efectos promovidos por el lenguaje neoliberal a través de la voz de un niño travestido. En este, el poeta inventa la voz de un niño que juega y desea ser como sus muñecas barbies -ícono cultural durante más de medio siglo- y que, tanto como en Ruiz y en Hernández, también se reconoce parte de una escena familiar disfuncional y fragmentada. Este sujeto describe, por una parte, la relación ambivalente que mantiene con su madre, a quien denomina como una figura falsa o postiza: "Mi madre falsa es mi madre biológica // La llamo falsa por usar lentes oscuros / para ocultar los ojos enrojecidos / y por decir que las cosas estaban bien" (63). Y, por otra, se refiere al vínculo que mantiene con su padre, a quien elabora bajo el signo del abandono: "Yo estaba enfermo y mi padre entró en la habitación / con un regalo / era un televisor en colores / El televisor permanecería encendido / el tiempo que yo permaneciera despierto / Desde entonces ya nunca más me sentiría solo" (20). La voz poética de Barrera articula su relato familiar desde la aguda consciencia de soledad que intentan revertir los juguetes de "niño" que le regala el padre ausente: junto con el televisor, una lámpara, un autito y una pelota, todos los cuales crean el simulacro de lo real ${ }^{17}$ mediante la fantasía compensatoria de lo humano familiar, fantasía que busca contrarrestar el vacío que asedia a este niño desde el interior de su casa-cuerpo simulacro.

Desde la intimidad "inofensiva-éxtima" ${ }^{18}$, puesta en escena, abierta, expuesta o teatralizada, Barrera construye un cuerpo-memoria perforado -con

17 Sobre el funcionamiento amnésico y anestésico de la cultura de la imagen en el mundo contemporáneo, especula Barrera en su poema "En Televisión" del libro Creatur (2009): "Si usted ha desarrollado el don de la televisión, es posible que conozca los misteriosos acontecimientos que suceden a otras personas en lugares ajenos. Es algo así como un sueño pero más real, algunas imágenes parecen tener vida propia y pueden decir más sobre usted que las observa que sobre ellas mismas en su distancia. Es como si usted habitase dentro de ellas y a la vez ellas fuesen construyendo su destino" (54).

18 Tamara Kamenszain utiliza el concepto lacaniano de "extimidad" para connotar, en poesía, la paradoja de una intimidad de lo privado que se muestra o exhibe en lo público: "[e]l término [...] significa exponer la propia intimidad en las vitrinas globales de la Web [...] esto es lo que sucede cuando en el arte actual se exhibe lo éxtimo: la pretensión no parece ser la de escandalizar, sino la de tornarlo inofensivo." (58-9). Las poéticas de la "intimidad 
las múltiples alusiones que el significante perforado del epíteto puede sugerir: excavar, traspasar, agujerear, taladrar, horadar, etc.- por la inmediatez de una serie de sucesos que limitan o, bien, destruyen la ingenuidad del niño en su casa-cuerpo simulacro. Junto a la naturalidad de sus pulsiones travestis, aquí nada es lo que parece ser, cuando todos participan, como advierte Roberto Onell, de algo así como una tragedia de títeres en tono menor, "soportable desde la clasificación en objetos animados [...] Personas que no son personas ni cosas que sean cosas $[\ldots]$ Todos son actores." (párr. $3^{\circ}$ ). Mediante la creación de sus personajes poéticos -el psicópata, la psicóloga, el esquizofrénico, la poetisa- y el travestismo de su identidad de género, Barrera crea una ficción familiar configurada tanto por la ausencia de cobijo materno, así como también por una función paterna que delega en el aparato massmediático la incorporación del sujeto en el campo cultural.

La operación de travestismo podemos cotejarla en la obsesión del niño por las distintas identidades y los distintos cuerpos-fenotipos de la muñeca Barbie, que actúa como espejo necesario para la introyección de un yo siempre cosificado (Castillo 52) ${ }^{19}$, pues la muñeca le permite al sujeto construir un mundo de fantasía al tiempo que manifestar su deseo de devenir-otro (devenirmujer o devenir-muñeca), al hacer expreso su anhelo de poseer un cuerpo de plástico que compense la soledad y el desamparo de su entorno más próximo. "No quería que ella y yo siguiéramos siendo tan distintos" (53), exclama.

éxtima" que ella analiza en la escritura de los poetas del 90 en Argentina sitúan el tratamiento de lo íntimo como centro: "ahora se trataría de rozar superficialmente la mayor cantidad de contenidos posibles con el solo fin de incluirlos. Eso sería hoy la intimidad: una tarea inclusiva, superficial y, se podría agregar a estas alturas, inofensiva. Es que tampoco gravita acá el peso del escándalo [...] ahora a aquella obscenidad del decir le corresponde una naturalización semántica donde todo es intercambiable" (45).

19 La condición de simulacro y el carácter travestido de sus personajes poéticos es una preocupación constante en la escritura de Gustavo Barrera. En "Al otro lado del mundo o de un espejo", de Adornos en el espacio vacio (2002), escribía: "El espejo tiene la posibilidad ilimitada de reflejar / los más variados objetos y situaciones, / sin embargo refleja una situación lamentable // El otro lado del mundo imita el otro lado / de otros mundos, progresivamente / hasta imitarlos a todos de una vez // De este modo las ciudades / se reproducen unas a otras y tienden / puentes / especulares e invisibles entre ellas" (31). Del mismo modo, en "Alicia teme por su vida" reescribe al personaje carrolliano según variadas descripciones que asocian la figura femenina a distintas funciones culturales de la mujer; todas ellas representadas por personajes de la cultura massmediática del siglo XX. Así, la describe como "la típica rubia oxigenada hipersexuada", "Alicia es la típica mujer histérica", "Alicia es la típica madre bondadosa del supermercado" o "Alicia es el típico andrógino ambiguo” (63). 
Y, más tarde, "Yo hubiera pedido ser de plástico" (58), contradiciendo el deseo de Pinocho cuando pidió al hada azul ser un niño de carne y hueso. Recordemos que el títere quería ser humano para volverse hijo de Geppetto, el carpintero que lo había tallado. Sin embargo, a contracorriente de su deseo por ingresar al campo afectivo de la subjetividad humana, en este texto el sujeto privilegia más bien un deseo de devenir-inhumano, explicado en la belleza desafectada de tiempo y espacio de las muñecas sintéticas:

Minutos antes yo disfrutaba de mi imagen maquillada en un espejo enfrentado con otro repetidas infinitas veces me preguntaba cuál de todos esos rostros semejantes y hermosos sería el verdadero (Barrera 9)

La disposición narcisista, en el juego del reflejo o del doble de sí, revela el conflicto identitario del hablante que, al no saber quién es, inviste su imagen en pos de una identidad especular, pues tal como afirma Kristeva, el narcisismo aparece siempre "como una primera organización identitaria, una primera autonomización" (87). De allí que la muñeca signifique para el sujeto travestido de Barrera una "leve apertura a la inquietud, a la posibilidad de lo imposible", en circunstancias que, de algún modo, ella insiste "en el ambiguo entre dos de la vida y la muerte: la vida en el mecanismo erótico que se deja entrever; y la muerte en el desmembramiento o, en su defecto, en la disfuncionalidad de las piezas que la constituyen" (Castillo 53) ${ }^{20}$.

Como la subjetividad performativa de Hernández, que deliraba al travestirse en una diva pop, la voz infantil producida por Barrera se traviste en una figura Barbie que lo salva de experimentar la carencia de afectos familiares. "Espejito, espejito", este sujeto recurre entonces a la fantasía de un narciso fragmentado en la multiplicidad de caretas asumida por la muñeca Barbie, y en cuyo delirio él encuentra su propia belleza, esto es, su insensibilidad

20

Para Simone de Beauvoir, la muñeca encarna la máxima expresión del narcisismo femenino debido al vínculo que establece entre cuerpo y artificio, un vínculo que manifiesta un tipo de amor que recrea la dualidad entre sujeto y objeto amoroso por medio de la paradójica relación entre el yo y su reflejo: "la muñeca representa el cuerpo en su totalidad y, por otro lado, es una cosa pasiva. En su virtud, la niña se sentirá animada a alienarse en su persona toda entera y a considerar a ésta como un dato inerte. Mientras el niño se busca en el pene en tanto sujeto autónomo, la niña mima a su muñeca y la adorna como sueña que adornen y la mimen a ella" (219). 
plástica ante la situación de abandono que emplaza tanto su espacio doméstico y cultural. Así, la puesta en escena del travestismo, en tanto que invención o ficción homoerótica, hace de la identidad de género una ficción cosmética que releva la identificación del sujeto con un objeto estereotipo como es la Barbie, la que se vuelve objeto de estudio en el contexto de un juego de roles, donde otro personaje de la historia familiar, "la psicóloga", le pide al sujeto llevar "sus disfraces", sus "vestidos de princesa" (73), para analizar sus patologías travestis:

La psicóloga me preguntó si podía llevar mis disfraces Era eso

Quería averiguar sobre los vestidos de princesa [...]

Grité golpeé la mesa

Y luego mentí acerca de todo (Barrera 73)

Las escenas fragmentadas de la historia familiar de este niño con síndrome Barbie, van revelando un deseo de travestismo que encarna la identificación de lo humano con lo artificial y que el sujeto afirma para sí en sus encuentros rituales con las muñecas, pero que niega frente a los demás, cuando su mundo de fantasía le pertenece solo a él, siendo no solo su protagonista sino también su custodio frente a los límites de lo real que él mismo establece. Así, por ejemplo, en el epígrafe que abre los poemas-episodios de la última sección de este poemario, se lee: "pajarillos de jaula me van pareciendo a mi misma mis sueños" (59), sintagma que, semiotizado en femenino ("a mí misma"), anuncia la posibilidad de concretar una autoimagen travesti por medio de la mezcla de características femeninas y masculinas: "La mitad derecha era la mitad del rostro de un hombre / La mitad izquierda era la mitad del rostro de una mujer" (65). Con estos versos, el sujeto se refiere al modo en que su rostro-mascarada ejecuta el acto de performar los significantes de una alquimia del cuerpo, que, en lugar de separar las identidades biopolíticamente asignadas como masculinas o femeninas, las reúne y pervierte. Por eso, al rememorar la pedagogía escolar de la autoridad, la violencia y el miedo, el sujeto recuerda que "Mis compañeros de colegio me llamaban Barón Assler / A veces me golpeaban / Otras veces huían" (65), haciendo referencia al personaje de Barón Ashler o Barón Ashura, que en la serie de manga japonés, Mazinger Z, posee un rostro mitad de hombre y mitad de mujer. Otro ícono cultural, de naturaleza televisiva, que el hablante actualiza como parte de los códigos de aprendizaje de la masculinidad hegemónica con que polemizan sus patologías travestis. 
Pero el ingreso del sujeto dentro de su fantasía Barbie se halla interrumpido por la amenaza de una realidad constante e inevitable que desmorona su delirio; esto es, la diferencia cultural y étnica que distingue su cuerpo del de las muñecas. De esta manera, nos indica cómo "Deseaba que Crystal Barbie tuviera el cabello negro // Sus ojos eran azules y sobre ellos había trazos lila / sus labios estaban pintados de fucsia y yo/ no quería que ella y yo siguiéramos siendo tan distintos" (53). El sujeto poético reconoce en los rasgos caucásicos de la Barbie norteamericana una distancia insalvable con respecto a su propio cuerpo mestizo, lo que motiva un efecto de repudio que intenta compensar por medio de su travestismo:

Tuve una sensación en el pecho me decía que esa ropa que llevaba puesta no me pertenecía

Que eran las vestimentas de un hombre

Sentí asco y las cambié

pero el desagrado era el mismo

Mi cuerpo estaba distinto

Me costaba respirar

Sentí tanto asco que no pude comer nada

Por fortuna no había nada que comer (Barrera 43)

El acto de travestismo del sujeto busca borrar las diferencias que existen con el cuerpo de la muñeca, pero se trata de un esfuerzo que le resulta vano, dado que su simulacro siempre limita con su sexo masculino y con su fisonomía mestiza. Fuera de su fantasía Barbie, experimenta un desarraigo que se manifiesta como asco y clausura de sus funciones vitales: no puede respirar ni comer; su imagen ante el espejo le resulta traumática y por eso la impugna y expulsa de su vista violentamente. Este sujeto no se puede simbolizar como otra cosa que no sea una réplica exacta del modelo Barbie que ocupa su deseo $\mathrm{y}$, por tanto, al desencontrarse con una imagen de sí que no se corresponde con ella (cuando Narciso ha sido traicionado por su propio mortal reflejo), se produce la crisis que el delirio le ofrece suturar.

Por otra parte, en el juego travesti que la voz poética mantiene con sus muñecas se produce la disgregación de la identidad de los sujetos una vez que esta se asocia al valor de cambio de los productos de consumo; pero, además, 
otro efecto problematizado son las formas de socialización transmitidas por la pulsión acumulativa que moviliza el deseo neoliberal. Se trata de un problema representado a partir de la narración que este sujeto realiza de un episodio particular relativo a su fantasía Barbie. En este, señala cómo en una ocasión él tiñe el pelo de su muñeca para que lo tenga negro como él, pero el experimento fracasa y le arruina toda su cara. Motivo por el que organiza un funeral, al que acuden incluso las muñecas "de plástico liviano que eran parte de la servidumbre" (51). Sin embargo, luego de unos días de deliberación, comenta:

\section{Decidí robar la cabeza de la Crystal Barbie de una vecina}

Su madre era asistente social y había traído desde un hogar de menores a una huérfana para que fuera su sirvienta

La sirvienta estaba sola y me abrió la puerta entré dije que no creía que estuviera sola y que debía dejarme pasar y recorrer la casa para verificar que decía la verdad [...]

Crystal Barbie recuperó el vestido la estola y las joyas la explicación que quiso dar ella a los demás era que había estado fuera para realizarse un procedimiento de cirugía estética (Barrera 57)

En la dinámica delirante de la identificación plena con la muñeca, Barrera representa la investidura criminal asociada a la expansión del mercado neoliberal, expresada en la dicotomía entre el amo y el siervo con que imagina su relación con la vecina. La escena de este sujeto, ocupando la propiedad ajena y desconociendo la dignidad del otro, le da actualidad a una de las características que emplaza el desarrollo de la economía en el contexto cultural contemporáneo, esto es, la "acumulación por desposesión" con que David Harvey se refiere a la producción de la riqueza neoliberal. Para Harvey, el neoliberalismo no es tanto una tecnología que genere nuevas riquezas como sí un aparato de redistribución basado en la apropiación ilegítima de la propiedad ajena $^{21}$. Por tanto, al recurrir al robo como un medio para recuperar

21 En palabras de Harvey, la "acumulación por desposesión" se efectúa a través de prácticas como "la mercantilización y privatización de la tierra y la expulsión forzosa de poblaciones campesinas [...]; la conversión de formas diversas de derechos de propiedad 
a la Barbie muerta, lo que hace Barrera es dar cuenta de la introyección en el sujeto de la ética neoliberal y de sus prácticas de desposesión del capital. A pesar de que este sujeto reconoce la pobreza de la vecina, no genera un vínculo solidario con ella, sino que imagina esta situación como una oportunidad para estafar. Por ello, no deja de resultar sugerente que el poeta decida poner la práctica del robo en el habla de un sujeto infantil, pues allí se elabora un aprendizaje temprano del lenguaje neoliberal, imbricado en esa industria de juguetes transnacionales, que nos enseñan desde pequeños a convertirnos en consumidores consumados, y quizás también, en pequeños ladrones.

\section{PARA CONCLUIR...}

Las subjetividades infantiles producidas por la poesía de los 2000 coinciden en decirse hijos de una mala leche que, en vez de alimentarlos, los ha malnutrido y precarizado. Mala leche que actúa como metáfora de las condiciones neoliberales de libre mercado (desigualdad social, hacinamiento, explotación laboral, criminalización de la infancia, entre otras), que revelan las nuevas formas de redistribución de la violencia histórica que ha recaído sobre los sectores más vulnerables, según los intereses productivos y programáticos que estos poetas le asignan a los poderes dominantes de la clase política en Chile hoy.

En los textos de Felipe Ruiz, Héctor Hernández y Gustavo Barrera, los niños son sujetos enfermos: psicóticos, violentos, abortados o travestidos; significantes todos de un cáncer social que polemiza con los discursos en torno al desarrollo supuesto que ha traído para nuestro país su introducción dentro de la economía global de mercado. Y es que, a contrapelo del exitismo tecnocrático, estos textos proyectan en el cuerpo herido y anémico de los niños del nuevo milenio el devenir de una ciudadanía que aún no consigue sus plenos derechos democráticos. Aquí, los niños habitan campamentos (viviendas de

(comunal, colectiva, estatal, etc.) en derechos exclusivos de propiedad privada [...]; la mercantilización de la fuerza de trabajo y la eliminación de modos de producción y de consumo alternativos (autóctonos); procesos coloniales, neocoloniales e imperiales de apropiación de activos (los recursos naturales entre ellos); y por último, la usura, el endeudamiento de la nación y, lo que es más devastador, el uso del sistema de crédito como un medio drástico de acumulación por desposesión" (175). 
emergencia) situados en los extramuros de la ciudad, se alimentan de comida chatarra y aprenden desde pequeños a jugar al consumo y a la segregación de clase. Se trata de imágenes que manifiestan, en todos los casos, una crítica mordaz a los alcances sociopolíticos de ese capitalismo salvaje que se impuso en el país bajo la administración de los gobiernos de la Concertación y sus políticas públicas de subsidio y asistencia social.

En los textos que hemos revisado, el lugar enunciativo de la infancia es una estrategia por medio de la cual los poetas representan la hegemonía del mercado sobre el campo cultural, en las voces de niños nacidos y criados bajo la hegemonía simbólica del neoliberalismo, cuyo poder cuestionan a través de la reiteración de significantes asociados al hambre, la violencia y la enfermedad. Es por esto que, al leer las voces infantiles creadas por la poesía de los últimos años, se repite y hace constante la producción de una estructura familiar fundada sobre la base de una violencia que coincide con la proyección de un espacio urbano trazado por casas misérrimas situadas en los sectores periféricos de la ciudad.

Los sujetos poéticos creados por Ruiz, Hernández y Barrera no se afilian a la retórica reconciliatoria utilizada por los gobiernos de la Concertación para referirse al proceso de transición democrática, sino que, más bien, hablan la lengua de una sociedad cuyo desarrollo está interrumpido y malformado. Estos poetas ficcionalizan las voces de niños vulnerados que han emergido del alcoholismo y del incesto, para representar, desde este origen anómalo, a la nación chilena como una madre abolida, de la que no han bebido más que mala leche.

BIBLIOGRAFÍA

Agamben, Giorgio. Infancia e historia. Buenos Aires: Adriana Hidalgo, 2007.

Barrera, Gustavo. Cuerpo perforado es una casa. Santiago: La Calabaza del Diablo, 2011. Creatur. Santiago: RIL, 2009. Adornos en el espacio vacio. Santiago: Aguilar / El Mercurio, 2002.

Bauman, Zygmunt. Vidas desperdiciadas. La modernidad y sus parias. Buenos Aires: Paidós, 2005.

Beauvoir, Simone de. El segundo sexo. Buenos Aires: Debolsillo, 2013.

Brito, Eugenia. Ficciones del muro: Brunet, Donoso, Eltit. Santiago: Cuarto Propio, 2014. Castillo, Alejandra. Imagen, cuerpo. Buenos Aires: La Cebra, 2015. 
Eltit, Diamela. Réplicas. Escritos sobre literatura, arte y política. Santiago: Planeta, 2016.

Guerrero, Claudio. "La infancia como espacio fantasmal en la poesía de Enrique Lihn". Acta literaria 40 (2010): 9-28.

Qué será de los niños que fuimos. Imaginarios de infancia en la poesía chilena. Valparaíso: Inubicalistas, 2017

Harvey, David. Breve historia del neoliberalismo. Trad. Ana Varela Mateos. Madrid: Akal, 2007. Hernández, Héctor. [guión]. Santiago: Lom, 2008.

"Panorama subjetivísimo de la novisísima poesía chilenísima". Letras s.5. 2004. Recuperado de: http://www.letras.mysite.com/hhm140704.htm

Instituto Nacional de Derechos Humanos. Situación de los Derechos Humanos en Chile. Informe Anual 2016. Santiago: INDH, 2016.

Kamenzsain, Tamara. Una intimidad inofensiva. Los que escriben con lo que hay. Buenos Aires: Eterna Cadencia, 2016.

Kristeva, Julia. Poderes de la perversión. Ciudad de México: Siglo XXI, 2013.

Maulén, Tamym. PAF. Buenos Aires: PorNos, 2011.

Moncada, Felipe. Territorios invisibles. Imaginarios de la poesía en provincia. Valparaíso: Ediciones Inubicalistas, 2016.

Munita Fritis, Víctor. Patria asignada. Santiago: Cuarto Propio, 2010.

Onell, Roberto. "Poemas que confirman la tendencia. La casa de Trotsky, de Cristián Gómez Olivares y Cuerpo perforado es una casa, de Gustavo Barrera Calderón”. Revista de Libros de El Mercurio, Domingo 16 de Noviembre de 2015.

Paredes, Pablo. Mi hijo Down. Buenos Aires: Black \& Bermelho, 2008.

"El final de fiesta". Frio en la noche latina. Antología. Santiago: Contrabando del bando en contra, 2005.

Pinos, Jaime. Criminal. Santiago: La Calabaza del Diablo, 2003.

Ramírez, Diego. El baile de los niños. Santiago: Ediciones del Temple, 2005.

Brian, el país de mi nombre en llamas. Santiago: Ceibo, 2015.

Rojas Canouet, Gonzalo. "La nueva palabra en su lugar: flujos e intentos profanatorios, el devenir ficcional”. Alpha 39 (2014): 69-78.

Ruiz, Felipe. Cobijo. Santiago: Lom, 2005.

Fosa común. Santiago: Fuga, 2009.

Said, Edward. El mundo, el texto, el crítico. Buenos Aires: Debate, 2004.

Sepúlveda, Magda. Ciudad quiltra. Poesía chilena (1973-2013). Santiago: Cuarto Propio, 2013. "La derrota de los pobladores: Cuevas, Zurita, Formoso". Alpha 33 (2011): 55-69.

Teillier, Jorge. "Los poetas de los lares. Nueva visión de la realidad en la poesía chilena". Boletín de la Universidad de Chile 56 (1965): 48-62.

Žižek, Slavoj. Viviendo en el final de los tiempos. Madrid: Akal, 2012. 